\title{
COVID-19 Stroke Apical Lung Exam Study: Is it Really an Accurate Diagnostic Method?
}

W

e have read with great interest the article by Dr J. Siddiqui et al, ${ }^{1}$ titled "COVID-19 Stroke Apical Lung Examination Study: A Diagnostic and Prognostic Imaging Biomarker in Suspected Acute Stroke," which was published in January 2021. We want to congratulate you in advance for addressing an important issue, such as the association between infection with Severe Acute Respiratory Syndrome coronavirus 2 (SARS-CoV-2) and a cerebrovascular accident, because of the impact that the latter has on both mortality and quality of life for patients. As the literature has shown, so far, the incidence of stroke in these patients is up to $5 \%{ }^{2}$

As we know, the standard reference test to establish the diagnosis of coronavirus disease 2019 (COVID-19) is reverse transcription-polymerase chain reaction. However, it is also widely known that its diagnostic accuracy is not $100 \%$, which is why other diagnostic methods such as chest tomography scans have been used because of their wide availability, speed in acquisition and interpretation, and diagnostic performance.

CT is not approved as a diagnostic method for COVID-19 and its main function is to classify the degree of pulmonary involvement instead of being a detection tool. In no circumstances does it replace the administration of the reverse transcription-polymerase chain reaction test in individuals who are suspected of having an infection. ${ }^{3}$

From the studies carried out so far and our experiences with patients with COVID-19, it is known that the main pulmonary involvement (especially in patients in the initial phase of the infection who probably do not yet present symptoms) is found

-- Indicates open access to non-subscribers at www.ajnr.org

http://dx.doi.org/10.3174/ajnr.A7141 in the posterior aspect and the pulmonary bases and is much smaller in the apices. The latter may even be respected in the initial stages of the disease. ${ }^{4}$ Therefore, we believe that using only the presence of ground-glass opacities in the lung apices is not a reliable or accurate biomarker for the diagnosis of COVID-19 and should not replace the acquisition of a complete chest tomography, much less the performance of reverse transcription-polymerase chain reaction testing.

Finally, we consider that it would have been interesting and accurate to include in the article which underlying diseases and other risks factors these patients had that could have influenced the occurrence of a cerebrovascular event.

\section{REFERENCES}

1. Siddiqui J, Bala F, Sciacca S, et al. COVID-19 stroke apical lung examination study: a diagnostic and prognostic imaging biomarker in suspected acute stroke. AJNR Am J Neuroradiol 2021;42:138-43 CrossRef Medline

2. Ortiz M, Valencia N, Moreno E, et al. ACV y COVID-19: una revisión de los estudios observacionales publicados en época de pandemia. Acta Neurológica Colombiana 2020;36:63-74 CrossRef

3. Khatami F, Saatchi M, Zadeh S.S. et al. A meta-analysis of accuracy and sensitivity of chest CT and RT-PCR in COVID-19 diagnosis. Scientific Reports 2020;10:22402 CrossRef Medline

4. Kwee T, Kwee R. Chest CT in COVID-19: what the radiologist needs to know. Radiographics 2020;40:1848-65 CrossRef Medline

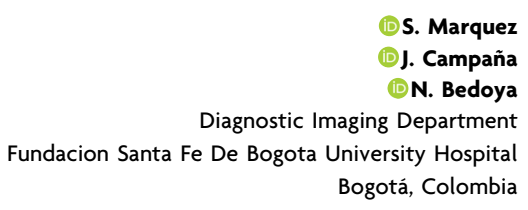

